\title{
Teacher Well-Being in EFL/ESL Classrooms
}

\author{
Zhong Li* \\ School of Foreign Languages, Xinyang College, Xinyang, China
}

A popular point in the last 20 years in academic and business settings is well-being at work that is in line with positive psychology, through which one can understand how to make working conditions enjoyable. Alternatively, teaching has been recognized as the most stressful career. Although, not many studies in the form of review have been carried out to focus on the notion of the well-being of teachers in English as a second language (ESL) or English as a foreign language (EFL). According to the literature review, the definition of this construct, the factors related to it, and the empirical studies in this domain are presented. In conclusion, the implications of well-being for teachers, school principals, teacher-trainers, and future researchers are provided, and new directions for future research are delineated.

Keywords: EFL/ESL classrooms, teacher well-being, positive psychology, working conditions, second language

\section{OPEN ACCESS}

Edited by:

Ali Derakhshan,

Golestan University, Iran

Reviewed by: Liqaa Habeb Al-Obaydi,

University of Diyala, Iraq Yongliang Wang,

Henan University, China

*Correspondence:

Zhong Li

leelizhong@163.com

Specialty section

This article was submitted to

Positive Psychology,

a section of the journal

Frontiers in Psychology

Received: 29 June 2021

Accepted: 09 July 2021

Published: 04 August 2021

Citation:

Li Z (2021) Teacher Well-Being

in EFL/ESL Classrooms.

Front. Psychol. 12:732412. doi: 10.3389/fpsyg.2021.732412

\section{INTRODUCTION}

The primary objectives of the educational framework are, undoubtedly, successful education, which covers different intricacies and is influenced by various variables. A bulk of research substantiates the possibility that teacher psychology is one of these variables (e.g., Van Horn et al., 2004; Acheson et al., 2016). When it comes to the language-learning psychology field, despite the great consideration of the psychology of the learners, moderately, the psychology of the teachers was not taken into consideration, which is as indispensable as the former in the language class (Mercer et al., 2016). In the last two decades, the developing popularity of positive psychology (PP) has caused an incredible shift away from the restrictive emphasis on issues in general psychology (Dewaele et al., 2019). Due to a call for a greater prominence on the positive aspect of life, PP has gained great momentum that considers human well-being and has investigated how individuals can work hard and how they can "thrive and flourish" (MacIntyre and Mercer, 2014, p. 154).

In addition, theories of PP in language acquisition study were adopted recently, and as it was stated by Mercer and MacIntyre (2014) that Lake (2013) was the first who presented PP perception in language acquisition, and with the advent of PP in this field, there has been a change from negative (paucities) to strong points (positive) (MacIntyre, 2016). It is proved that positive emotions are associated with attitudes toward the learning circumstances, the teacher and the course, and motivation to acquire English (Dewaele and Li, 2020). Well-being is an active construct of PP which refers to the way a person thinks, perceives, and circumstances at a prearranged period (Greenfield, 2015). When talking about well-being in PP, the construct of flourishing (having an enthusiasm for life) is often taken into account (Kern et al., 2016). In the English as a foreign language (EFL) setting, teacher well-being may also be endangered by numerous issues, such as deficient language skills, lack of linguistic knowledge, the absence of confidence (Mousavi, 2007; Talbot and Mercer, 2018), and the stress imposed on them due to a heavy workload (Clipa and Boghean, 2015). 
Other constructs that support teacher well-being are resilience and self-efficacy. So, it is proposed that flourishing is not contradicted to the manifestation of stress in the lives of people but instead changes the viewpoints toward the positive qualities that assist a person in managing difficulties (Greenfield, 2015).

So far, most researchers have broadly focused on negative emotions to examine their adverse impacts on the language learning process (e.g., Saboori and Pishghadam, 2016; Özdemir and Demir, 2019); however, positive emotions have been ignored in most academic research and little attention has been given to the changes that they can make to English as a second language (ESL)/EFL classes as Lantolf and Swain (2019) stated that the role of positive emotions is increasing across existing limitations. Furthermore, several studies have been conducted to focus on teacher well-being; however, still limited evidence is presented on the history, definitions, and determinants of wellbeing relevant for ESL/EFL teachers, which seems to be necessary for language-learning quality (Weiland, 2021). As a result, to reinforce the emergent attention to PP in ESL/EFL classes and teaching inquiries, in this review article, the researcher tried to clarify the well-being of teachers, factors affecting it, and the previous studies which have been carried out in this domain.

\section{THE CONCEPT OF THE WELL-BEING OF THE TEACHER}

Butler and Kern (2016) referred to several theories developed by PP scholars to define the well-being construct. The study of well-being was in two systems, subjective well-being and psychological well-being (PWB), measured by hedonic and eudemonic methods, respectively (Keyes, 2002). Even though both have values in research on the well-being of teachers, the hedonic perspective, especially apparent in research on "subjective well-being," (Diener and Lucas, 2000) contends that well-being fixates principally on expanding delight and diminishing agony, and will, underscore outer impacts on sensations of well-being instead of inner sources, including inspirations, yearnings, and wants of the teachers. As opposed to the hedonic perspective, the eudaimonic one deals with human thriving, which is characterized as a psychosocial development that incorporates fulfillment and good connections, feeling skillful and certain, and accepting that life is significant and intentional and underscores both satisfaction and seriousness (Diener et al., 2010). Flourishing is the objective of PP that refers to well-being using great levels of PERMA in life, which as stated by Seligman (2018), signifies positive emotion (P), engagement with actions that consider powers of the individual (E), increasing constructive personal relationships (R), finding meaning by helping a reason further than oneself $(M)$, and identifying parts of achievement and success (A). Through this model, well-being has arisen from the relations of positivity in all these elements, which refers to the eudemonic view of wellbeing (Mercer and Gregersen, 2020). When it comes to teaching, well-being has been investigated concerning satisfaction of the teachers with their positions and the feelings that are brought about by their professional experiences (Margolis et al., 2014; Collie et al., 2016).
The expansion of studies on well-being was proposed by Diener (2009), containing the area of work that refers to the healthy functioning of an individual in their work setting. Coleman (2009) makes the significance of well-being for the teaching career clear when contending that barely does it make sense to handle the emotional health of students in a school without taking care of the emotional health of the staff. The wellbeing of teachers is noteworthy because of its results for learners and schools, for example, teachers encountering low well-being in the working environment might be less useful and be more inclined to leave work (Boyd et al., 2006).

\section{Factors Affecting the Well-Being}

Well-being has several dimensions that are dependent upon a collection of internal and external aspects (Benevene et al., 2018). The aspects which affect teacher well-being are either positive or negative (Zadworna-Cieślak and Karolina, 2018). Among negative aspects, stress and burnout can play key roles, which were studied earlier regarding negative emotions of teachers (Capone et al., 2019; Derakhshan et al., 2021).

As Ryan and Deci (2001) postulated, occupational well-being among teachers, which is related to ideal mental capacity and their positive work experience, has been characterized by the existence of positive dimensions, such as work fulfillment and interests in work (Benevene et al., 2018). In addition, self-efficacy is the first element which is a fundamental piece of well-being that may influence self-inspiration as well as both personal and professional life directions (Bandura, 2000). Furthermore, the self-efficacy of the teacher is characterized by the self-decisions of teachers concerning their capability of influencing learner results, particularly of learners who seem unmotivated or who are hard to instruct (Ross et al., 2012).

Besides, the other positive factors or strategies to deal with stress, which subsequently affect well-being, are resilience, mindfulness, and emotional regulation (Lovewell, 2012; Zadworna-Cieślak and Karolina, 2018). Resilience is a fundamental piece of human life (Bullough, 2011), whereas mindfulness refers to an ability to attend freely to what is occurring in the ongoing moment experience of an individual (Creswell and Lindsay, 2014), and emotional regulation is the capability a person to control when and how to encounter emotions in the activity they are interested in Yin et al. (2016). They are both regarded as the conditions of supporting good teaching in challenging conditions to manage stress and promote wellbeing (Bullough, 2011; Garland et al., 2011). As a result, teachers with high degrees of stress and burnout, and without satisfactory managing abilities and strategies, such as resilience, mindfulness practices, and emotional regulation, were not successful in their job and consequently cannot fulfill the accomplishment of their students (Herman et al., 2017).

\section{EMPIRICAL STUDIES}

Greenier et al. (2021) proved the effect of emotional regulation and PWB as predictors of work engagement in both British and Iranian teachers, and the results indicated that both variables 
predicted work engagement for the participants, even though the association of the PWB and work engagement was more resilient for British teachers. Numerous studies (e.g., Svence and Majors, 2015; Brouskeli et al., 2018) have revealed a relationship between resilience and the well-being of teachers. In addition, a study by Barbieri et al. (2019) evinced how positive insight of teachers on the working conditions may improve a significant level of wellbeing at work, and how these aspects are in line with the job satisfaction of the teachers. Besides, a study by Han et al. (2020) examined the relationships among challenging job demands and resources (JD-R) and the effect of the efficacy of teachers among university professors. These findings proved the effective use of the JD-R model and the impact of teacher efficacy on the correlation between the professional features and the well-being of the teachers.

\section{IMPLICATIONS AND FUTURE DIRECTIONS}

Based on this mini-review that focuses on the well-being of the teacher as positive emotions of the teacher, many pedagogical implications were provided for different groups in EFL/ESL settings, such as teachers, school principals, teacher-trainers, and researchers.

The essence of any teaching organization is its teachers, and their well-being should be dominant in the educational

\section{REFERENCES}

Acheson, K., Taylor, J., and Luna, K. (2016). The burnout spiral: the emotion labor of five rural U.S. foreign language teachers. Modern Lang. J. 100, 522-537. doi: $10.1111 / \bmod 1.12333$

Bandura, A. (2000). "Cultivate self-efficacy for personal and organizational effectiveness," in Handbook of Principles of Organizational Behavior, ed. E. A. Locke (Oxford: Blackwell), 120-136.

Barbieri, B., Sulis, I., Porcu, M., and Toland, M. D. (2019). Italian teachers' wellbeing within the high school context: evidence from a large scale survey. Front. Psychol. 10:1926. doi: 10.3389/fpsyg.2019.01926

Benevene, P., Ittan, M. M., and Cortini, M. (2018). Self-esteem and happiness as predictors of school teachers' health: the mediating role of job satisfaction. Front. Psychol. 9:933. doi: 10.3389/fpsyg.2018 00933

Boyd, D. J., Grossman, P., Lankford, H., Loeb, S., Michelli, N. M., and Wyckoff, J. (2006). Complex by design: investigating pathways into teaching in New York City schools. J. Teach. Educ. 57, 155-166. doi: 10.1177/0022487105285943

Brouskeli, V., Kaltsi, V., and Loumakou, M. (2018). Resilience and occupational well-being of secondary education teachers in Greece. Issues Educ. Res. 28, 43-60.

Bullough, R. V. (2011). "Hope, happiness, teaching and learning," in New Understandings of Teacher's Work: Emotions and Educational Change, eds C. Day and J. C. K. Lee (New York, NY: Springer), 17-32.

Butler, J., and Kern, M. L. (2016). The PERMA-profiler: a brief multidimensional measure of flourishing. Int. J. Wellbeing 6, 1-48. doi: 10.5502/ijw.v6i3.526

Capone, V., Joshanloo, M., and Park, M. S. A. (2019). Burnout, depression, efficacy beliefs, and work-related variables among school teachers. Int. J. Educ. Res. 95, 97-108. doi: 10.1016/j.ijer.2019.02.001

Clipa, O., and Boghean, A. (2015). Stress factors and solutions for the phenomenon of burnout of preschool teachers. Procedia Soc. Behav. Sci. 180, 907-915. doi: 10.1016/j.sbspro.2015.02.241

Coleman, J. (2009). Well-being in schools: empirical measure or politician's dream? Oxf. Rev. Educ. 35, 281-292. doi: 10.1080/03054980902934548 context not only to improve the ability of the learners but also to motivate and encourage them to participate in classroom activities. Teachers seek an approach that does not stress them and would give them more scope to apply creative teaching methods and give interesting exercises. Well-being and the remarkable difficulties that teachers face in guaranteeing health in an EFL/ESL setting is still a significant thought to better maintain and support teachers in their expert work. The trainers of the teachers should be educated regarding PP, and schools should teach well-being strategies, such as resilience, mindfulness, and emotional regulation alongside scholarly ones through proficient improvement to their teachers to help lighten the inescapable pressure and stress that are met in their profession. Besides, school principals need to provide a healthy setting for their teachers to support their well-being that can foster a successful classroom. The present review is set to raise the prominent role of PP, in general, and the well-being of teachers, in particular, to encourage teachers and researchers to bear these issues in mind and give better ideas for the progress in this field, and, accordingly, contribute to their awareness of the mechanism for establishing well-being among EFL/ESL teachers.

\section{AUTHOR CONTRIBUTIONS}

ZL read the relevant literature and presented the implications of well-being for the research in SLA.

Collie, R. J., Shapka, J. D., Perry, N. E., and Martin, A. J. (2016). Teachers' psychological functioning in the workplace: exploring the roles of contextual beliefs, need satisfaction, and personal characteristics. J. Educ. Psychol. 108, 788-799. doi: 10.1037/edu0000088

Creswell, J. D., and Lindsay, E. K. (2014). How does mindfulness training affect health? A mindfulness stress buffering account. Curr. Dir. Psychol. Sci. 23, 401-407. doi: 10.1177/0963721414547415

Derakhshan, A., Kruk, M., Mehdizadeh, M., and Pawlak, M. (2021). Boredom in online classes in the Iranian EFL context: sources and solutions. System 102556. doi: 10.1016/j.system.2021.102556

Dewaele, J. M., and Li, C. (2020). Emotions in second language acquisition: a critical review and research agenda. Foreign Lang. World 196, 34-49.

Dewaele, J. M., Chen, X., Padilla, A. M., and Lake, J. (2019). The flowering of positive psychology in foreign language teaching and acquisition research. Front. Psychol. 10:2128. doi: 10.3389/fpsyg.2019.02128

Diener, E. (2009). "Positive psychology: past, present, and future," in Oxford Handbook of Positive Psychology, eds S. J. Lopez and C. R. Snyder (Oxford: Oxford University Press), 7-11.

Diener, E., and Lucas, R. E. (2000). Explaining differences in societal levels of happiness: relative standards, need fulfillment, culture, and evaluation theory. J. Happiness Stud. 1, 41-78.

Diener, E., Wirtz, D., Tov, W., Kim-Prieto, C., Choi, D.-Y., Oishi, S., et al. (2010). New well-being measures: short scales to assess flourishing and positive and negative feelings. Soc. Indic. Res. 97, 143-156. doi: 10.1007/s11205-009-9493-y

Garland, E. L., Gaylord, S. A., and Fredrickson, B. L. (2011). Positive reappraisal mediates the stress-reductive effects of mindfulness: an upward spiral process. Mindfulness 2, 59-67. doi: 10.1007/s12671-011-0043-8

Greenfield, B. (2015). How can teacher resilience be protected and promoted? Educ. Child Psychol. 32, 53-68.

Greenier, V., Derakhshan, A., and Fathi, J. (2021). Emotion regulation and psychological well-being in teacher work engagement: a case of British and Iranian English language teachers. System 97:102446. doi: 10.1016/j.system. 2020.102446 
Han, J., Yin, H., Wang, J., and Bai, Y. (2020). Challenge job demands and job resources to university teacher well-being: the mediation of teacher efficacy. Stud. High. Educ. 45, 1771-1785. doi: 10.1080/03075079.2019.1594180

Herman, K. C., Hickmon-Rosa, J. E., and Reinke, W. M. (2017). Empirically derived profiles of teacher stress, burnout, self-efficacy, and coping and associated student outcomes. J. Posit. Behav. Interv. 20, 90-100. doi: 10.1177/ 1098300717732066

Kern, M. L., Benson, L., Steinberg, E. A., and Steinberg, L. (2016). The EPOCH measure of adolescent well-being. Psychol. Assess. 28, 586-594. doi: 10.1037/ pas0000201

Keyes, C. (2002). The mental health continuum: from languishing to flourishing in life. J. Health Soc. Behav. 43, 207-222. doi: 10.2307/3090197

Lake, J. (2013). "Positive L2 self: linking positive psychology with L2 motivation," in Language Learning Motivation in Japan, eds M. Apple, D. Da Silva, and T. Fellner (Bristol: Multilingual Matters), 225-244. doi: 10.21832/9781783090518015

Lantolf, J. P., and Swain, M. (2019). On the emotion-cognition dialectic: a sociocultural response to prior. Mod. Lang. J. 103, 528-530. doi: 10.1111/modl. 12574

Lovewell, K. (2012). Every Teacher Matters. St Albans: Ecademy Press.

MacIntyre, P. D. (2016). "So far so good: an overview of positive psychology and its contributions to SLA," in Positive Psychology Perspectives on Foreign Language Learning and Teaching, eds D. Gabryś-Barker and D. Gałajda (Switzerland: Springer), 3-20. doi: 10.1007/978-3-319-32954-3_1

MacIntyre, P. D., and Mercer, S. (2014). Introducing positive psychology to SLA. Stud. Second Lang. Learn. Teach. 4, 153-172. doi: 10.14746/ssllt.2014.4.2.2

Margolis, J., Hodge, A., and Alexandrou, A. (2014). The teacher educator's role in promoting institutional versus individual teacher well-being. J. Educ. Teach. 40, 391-408. doi: 10.1080/02607476.2014.929382

Mercer, S., and Gregersen, T. (2020). Teacher Wellbeing. Oxford: Oxford University Press.

Mercer, S., and MacIntyre, P. D. (2014). Introducing positive psychology to SLA. Stud. Second Lang. Learn. Teach. 4, 153-172. doi: 10.14746/ssllt.2014.4.2.2

Mercer, S., Oberdorfer, P., and Saleem, M. (2016). "Helping language teachers to thrive: using positive psychology to promote teachers" professional well-being," in Positive Psychology Perspectives on Foreign Language Learning and Teaching, eds D. Gabryś-Barker and D. Gałajda (Switzerland: Springer), 213-229. doi: 10.1007/978-3-319-32954-3_12

Mousavi, E. S. (2007). Exploring 'teacher stress' in non-native and native teachers of EFL. ELTED 10, 33-41.

Özdemir, B., and Demir, A. (2019). Romantic relationship satisfaction, age, course load, satisfaction with income and parental status as predictors of instructors' burnout: evidence from a correlational study. Curr. Psychol. 38, 1083-1098. doi: 10.1007/s12144-017-9724-3
Ross, S. W., Romer, N., and Horner, R. H. (2012). Teacher well-being and the implementation of schoolwide positive behavior interventions and supports. J. Posit. Behav. Interv. 14, 118-128. doi: 10.1177/1098300711413820

Ryan, R. M., and Deci, E. L. (2001). On happiness and human potentials: a review of research on hedonic and eudaimonic well-being. Annu. Rev. Psychol. 52, 141-166. doi: 10.1146/annurev.psych.52.1.141

Saboori, F., and Pishghadam, R. (2016). English language teachers' burnout within the cultural dimensions framework. Asia Pac. Educ. Res. 25, 677-687. doi: 10.1007/s40299-016-0297-y

Seligman, M. (2018). PERMA and the building blocks of well-being. J. Posit. Psychol. 13, 333-335. doi: 10.1080/17439760.2018.1437466

Svence, G., and Majors, M. (2015). Correlation of well-being with resilience and age. Problem Psychol. 21st Century 9, 45-56.

Talbot, K., and Mercer, S. (2018). Exploring university ESL/ EFL teachers' emotional well-being and emotional regulation in the United States, Japan and Austria. Chin. J. Appl. Linguist. 41, 410-432. doi: 10.1515/cjal-2018-0031

Van Horn, J. E., Taris, T. W., Schaufeli, W. B., and Schreurs, P. J. G. (2004). The structure of occupational well-being: a study among dutch teachers. J. Occupat. Organ. Psychol. 77, 365-375.

Weiland, A. (2021). Teacher well-being: voices in the field. Teach. Teach. Educ. 99:103250. doi: 10.1016/j.tate.2020.103250

Yin, H., Huang, S., and Wang, W. (2016). Work environment characteristics and teacher well-being: the mediation of emotion regulation strategies. Int. J. Environ. Res. Public Health 13, 907-923. doi: 10.3390/ijerph13090 907

Zadworna-Cieślak, M., and Karolina, K. (2018). Psychological well-being in the teaching profession. Edukacja Dorostych 2, 199-209.

Conflict of Interest: The author declares that the research was conducted in the absence of any commercial or financial relationships that could be construed as a potential conflict of interest.

Publisher's Note: All claims expressed in this article are solely those of the authors and do not necessarily represent those of their affiliated organizations, or those of the publisher, the editors and the reviewers. Any product that may be evaluated in this article, or claim that may be made by its manufacturer, is not guaranteed or endorsed by the publisher.

Copyright (c) $2021 \mathrm{Li}$. This is an open-access article distributed under the terms of the Creative Commons Attribution License (CC BY). The use, distribution or reproduction in other forums is permitted, provided the original author(s) and the copyright owner(s) are credited and that the original publication in this journal is cited, in accordance with accepted academic practice. No use, distribution or reproduction is permitted which does not comply with these terms. 